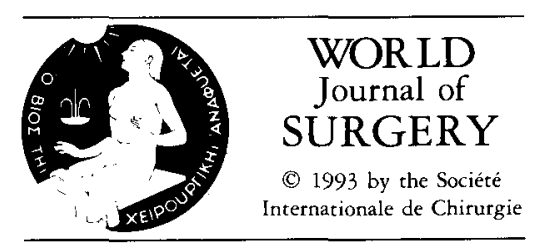

\title{
Role of Extracorporeal Shock Wave Lithotripsy in Hepato-Biliary-Pancreatic Surgery
}

\author{
René L. van der Hul, M.D., Peter W. Plaisier, M.D., Onno T. Terpstra, M.D., and Hajo A. Bruining, M.D. \\ Department of Surgery, University Hospital Rotterdam, Rotterdam, The Netherlands; and Department of Surgery, University Hospital \\ Leiden, Leiden, The Netherlands
}

\begin{abstract}
Since the early 1980s extracorporeal shock wave lithotripsy (ESWL) has partially replaced major operative procedures in various fields of surgery. In the interest of the patient, it is important to determine the exact role of ESWL in surgery. Comparing our own prospectively followed patients with other patient series, we have tried to assess this role. We treated 133 patients with cholecystolithiasis, 80 patients with choledocholithiasis, and 17 patients with pancreatic stones using a second-generation lithotriptor, the Siemens Lithostar (Siemens, Erlangen, Germany). The results suggest a limited role of ESWL for cholecystolithiasis, in which it is reserved for patients with high operative risk and patients who reject an operation. For choledocholithiasis ESWL seems to become an integral part of the treatment in the elderly patient in whom endoscopic stone removal proved impossible. Finally, ESWL could become a first option for the treatment of intractable pain in patients with chronic calcifying pancreatitis.
\end{abstract}

Shock waves, which can be used to disintegrate stones because of their physical characteristics, can be generated by three methods [1-3]. Since 1980 extracorporeal shock wave lithotripsy (ESWL) has been used in the case of urolithiasis and has replaced surgical treatment almost entirely [4, 5]. ESWL of gallbladder stones has been applied since $1985[6,7]$, and the first reports on ESWL of common bile duct stones and pancreatic stones appeared in 1989 [8, 9]. Despite the initial enthusiasm, restrictions for ESWL of gallbladder stones especially soon became evident. Rigid entry criteria, expensive adjuvant dissolution therapy, moderate results, and the possibility of stone recurrence after gallbladder-preserving therapies are major drawbacks [7, 10-17]. ESWL of common bile duct stones is useful in patients in whom endoscopic removal proves impossible [8, 18-21]. ESWL of pancreatic stones in chronic calcifying pancreatitis is still relatively unknown but seems effective [22]. The morbidity and mortality associated with ESWL are minimal $[7,8,11-13,18-22]$ and compare favorably to those with surgery. Therefore we have tried to assess the exact role of ESWL in this field with our own prospectively followed patients and other patient series.

Offprint requests: R.L. van der Hul, M.D., Department of Surgery, University Hospital Rotterdam, Dr. Molewaterplein 40, 3015 GD Rotterdam, The Netherlands.

\section{Patients and Methods}

Using a so-called second-generation lithotriptor, the Siemens Lithostar (Siemens, Erlangen, Germany), which operates on a electromagnetic principle, we treated patients suffering from cholecystolithiasis ( $n=133$, group I), choledocholithiasis $(n=$ 80, group II), and pancreatic stones ( $n=17$, group III). Characteristics of these patients are depicted in Table 1 , and entry criteria for ESWL in the three groups are shown in Table 2.

\section{Group I}

All patients were treated on an outpatient basis. Directly after the first ESWL session, adjuvant oral bile acid (OBA) therapy (urso- and chenodeoxycholate) was started. Ten days after each session an ultrasound examination (US) was done to determine the fragmentation result. If fragments remained larger than 5 $\mathrm{mm}$ after repeated sessions, ESWL was considered a failure, and cholecystectomy was advised. US was performed at regular intervals ( 3 months, 6 months, 1 year, 1.5 years, and 2 years) after the first session. If US did not demonstrate stone material at two consecutive occasions, clearance of the gallbladder was assumed and the OBA therapy stopped.

\section{Group II}

All patients had one or more of the symptoms, depicted in Table 1. The stones were visualized by radiology and injection of contrast medium in the bile ducts via a biliary drain (Table 1). In 11 patients the biliary sphincter could not be reached at endoscopy. In those patients and in seven others, percutaneous drains and $T$ tubes were used. Of the 47 patients without gallbladder, 12 had had a cholecystectomy recently and had also undergone a choledochotomy. In these patients, overlooked common bile duct stones were discovered on a postoperative $T$ tube cholangiogram. The possibility of spontaneous clearance of the stones after endoscopic sphincterotomy was thought to be low because of the large size and impacted character of the stones.

All treatments were performed under antibiotic coverage and 
Table 1. Patient characteristics before ESWL treatment.

\begin{tabular}{lcll}
\hline Characteristic & Group I & Group II & Group III \\
\hline Patients (M/F) & $133(34 / 99)$ & $80(33 / 47)$ & $17(10 / 7)$ \\
Age, mean (range) & $49(24-81)$ & $73(27-91)$ & $42(19-55)$ \\
(years) & & & \\
Stones (no. patients) & $70(53 \%)$ & $34(43 \%)$ & $6(35 \%)$ \\
1 & $55(41 \%)$ & $32(40 \%)$ & $7(41 \%)$ \\
$2-5$ & $8(6 \%)$ & $14(18 \%)$ & $4(24 \%)$ \\
$6-10$ & $17(5-40)$ & $25(10-50)$ & $21(14-40)$ \\
Stone diameter mean & & & \\
(range) (mm) & & $69(86 \%)$ & $17(100 \%)$ \\
Patients (no.) with & & $62(78 \%)$ & \\
ES & & $6(8 \%)$ & \\
Biliary drain & $12(15 \%)$ & \\
$\quad$ NBD & & $39(49 \%)$ & \\
PTD & & $36(45 \%)$ & \\
T-tube & $16(20 \%)$ & \\
Symptoms & & \\
Biliary colic & & $47(59 \%)$ & $3(18 \%)$ \\
Jaundice & & & \\
Fever $>38.5^{\circ} \mathrm{C}$ & & & $10(59 \%)$ \\
Cholecystectomy & & & \\
Previous & & & \\
pancreatic & & & \\
surgery & & & \\
History of alcohol & & & \\
abuse & & &
\end{tabular}

ES: endoscopic sphincterotomy; NBD: nasobiliary drain; PTD: percutaneous transhepatic drain.

Table 2. Criteria for ESWL of gallbladder, common bile duct, or pancreatic stones.

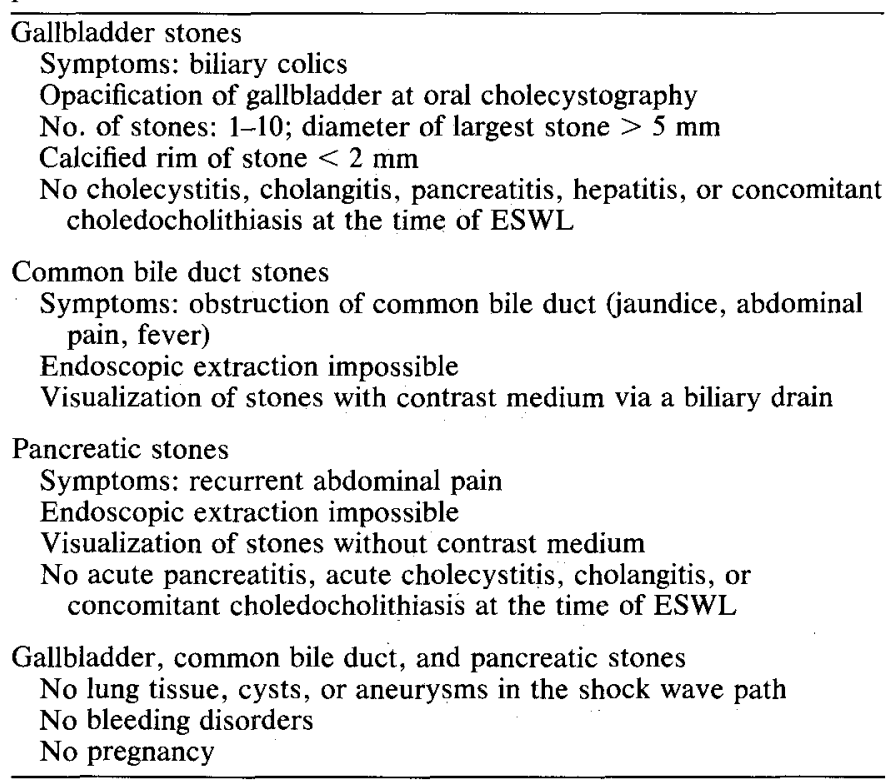

continuous lavage of the bile ducts with 4 liters of sterile water per 24 hours. Shortly after ESWL the result was evaluated by cholangiography. In case of fragmentation (reduction of stone diameter, lines of contrast medium visible within the stone, or quick disappearance of the contrast medium from the biliary tree), cholangiography was repeated after 2 days of lavage. In the case of remaining fragments, a new endoscopic or percutaneous stone extraction was attempted. If it was not successful
Table 3. Characteristics of ESWL sessions in three groups of patients.

\begin{tabular}{llll}
\hline Characteristic & $\begin{array}{l}\text { Group I } \\
(n=133)\end{array}$ & $\begin{array}{l}\text { Group II } \\
(n=80)\end{array}$ & $\begin{array}{l}\text { Group III } \\
(n=17)\end{array}$ \\
\hline $\begin{array}{l}\text { Sessions/patient } \\
\text { (range) }\end{array}$ & $2.2(1-7)$ & $1.9(1-4)$ & $1.9(1-4)$ \\
$\begin{array}{l}\text { SW/session } \\
\text { (range) }\end{array}$ & $2817(75-4000)$ & $4703(1200-6000)$ & $4660(1000-8000)$ \\
$\begin{array}{l}\text { Duration } \\
\text { (min)/ }\end{array}$ & $62(35-210)$ & $64(30-150)$ & $73(20-105)$ \\
session & & & \\
$\quad$ (range) & & & \\
Patients (no.) & 0 & 1 & 1 \\
$\quad$ GA & 133 & 71 & 1 \\
AS & 0 & 8 & 1 \\
No GA/AS & & & \\
\hline
\end{tabular}

SW: shock waves; GA: general anesthesia; AS: analgo-sedation.

or in cases where stone fragmentation was never demonstrated, the patient underwent an elective bile duct exploration or had an endoprosthesis placed in the common bile duct.

\section{Group III}

The diagnosis "chronic pancreatitis" was based on the patient's history (chronic upper abdominal pain or recurrent attacks of upper abdominal pain), the presence of calcifications in the pancreatic region on plain abdominal roentgenography, and the radiologic aspect of chronic pancreatitis on endoscopic retrograde cholangiopancreatography [23]. All patients were treated under antibiotic coverage. In 15 patients the stones could be visualized as calcifications by radiology alone. Shock waves were focused on these calcifications. In 2 patients additional injection of contrast medium via a nasopancreatic drain was necessary for visualization of the stones because of a low calcification grade. After the ESWL treatment a plain abdominal roentgenogram was obtained. If stone fragmentation was observed (clear change of contour of stone), another endoscopic stone extraction was attempted, after which a nasopancreatic drain was left in place for lavage (2 liters sterile water per 24 hours). If no stone material was observed, spontaneous clearance of the duct was assumed. If ESWL repeatedly failed in fragmenting the stones, an operation was contemplated.

Statistics were performed using the test for comparing proportions with binominal distributions and the Wilcoxon test for matched pairs.

\section{Results}

Table 3 summarizes the characteristics of the ESWL sessions for all three groups of patients. Table 4 depicts the fragmentation and clearance rates for all three groups. For group I the median follow-up (range) is 14 months ( $1-45$ months), in group II 23 months (1-50 months), and group III 20 months (3-41 months).

\section{Group I}

Stone fragmentation (decrease of diameter of the largest stone $>25 \%$ ) could be achieved in most patients (89\%); but after 
Table 4. Results of ESWL of the gallbladder, common bile duct, and pancreatic stones.

\begin{tabular}{|c|c|c|c|c|}
\hline Group & $\begin{array}{l}\text { No } \\
\text { fragmentation }\end{array}$ & Fragmentation & $\rightarrow$ & Stone clearance \\
\hline $\mathrm{I}(n=133)$ & $\begin{array}{l}15(11 \%) \\
8 \text { Expectant } \\
7 \text { Operated }\end{array}$ & $\begin{array}{l}118(89 \%) \\
52 \text { Still OBA } \\
23 \text { Operated }\end{array}$ & $\rightarrow$ & $\begin{array}{l}43(32 \%) \\
6 \text { Recurrence } \\
4 \text { Expectant } \\
1 \text { Operated } \\
1 \text { OBA }\end{array}$ \\
\hline \multirow[t]{2}{*}{$\mathrm{II}(n=80)$} & $\begin{array}{l}14(18 \%) \\
\text { All operated } \\
\text { electively }\end{array}$ & $\begin{array}{l}66(83 \%) \\
6 \text { Endoprosth }\end{array}$ & $\rightarrow$ & $\begin{array}{l}52(65 \%) \\
14 \text { Lavage }\end{array}$ \\
\hline & & $\begin{array}{c}6 \text { Operated } \\
\text { electively } \\
2 \text { Operated } \\
\text { emergently }\end{array}$ & & $\begin{array}{l}34 \text { Endoscopic } \\
\text { extraction } \\
4 \text { Percutaneous } \\
\text { extraction }\end{array}$ \\
\hline III $(n=17)$ & $\begin{array}{l}4(24 \%) \\
1 \text { Expectant } \\
3 \text { Operated }\end{array}$ & $\begin{aligned} & 13(76 \%) \\
& 4 \text { Pain } \\
& \text { relief } \\
& 2 \text { Operated }\end{aligned}$ & $\rightarrow$ & $\begin{array}{l}7(41 \%) \\
\text { All pain relief }\end{array}$ \\
\hline
\end{tabular}

OBA: oral bile acid therapy; endoprosth: endoprosthesis.

adjuvant OBA therapy stone clearance could be achieved in only $32 \%$ of the patients to date. In the remainder of the patients, OBA therapy continues or a cholecystectomy has been undertaken because of persistent biliary complaints or insufficient stone fragmentation. Patients with a solitary stone had a significantly better chance to become stone-free than patients with multiple stones: 26 of $52(51 \%)$ versus 5 of 60 (13\%), respectively, after 1 year of follow-up ( $p<0.001$ : two sample proportion test).

Fourteen percent of patients with stone clearance (6/43) had stone recurrence: four of the six were not symptomatic, one underwent a cholecystectomy, and in one OBA therapy was restarted.

A total of 57 patients ( $43 \%$ ) had biliary colic shortly after the ESWL treatment. Other complications were obstruction of the common bile duct in nine patients (7\%), five of whom became jaundiced and in four of whom pancreatitis developed. Two patients (1.5\%) had transient hematuria, one had acute cholecystitis after ESWL. OBA therapy resulted in diarhea in 15 patients (11\%), which resolved in all cases after lowering the dose of OBA for 2 weeks. No mortality was observed.

\section{Group II}

Stone clearance was achieved in 52 patients (65\%); in 14 cases biliary lavage was sufficient to clear the bile ducts; in 34 cases the remaining fragments were extracted endoscopically and in 4 cases percutaneously. In case of failure of the additional endoscopic or percutaneous attempts $(n=14,18 \%)$, the final treatment-taking into account the patient's physical statusconsisted in placing an endoprosthesis past the fragmented stones $(n=6)$ or undertaking an elective bile duct exploration $(n=6)$. In two cases emergency surgery was necessary after complications of an endoscopic procedure (one perforation of the common bile duct with a Dormia basket, one arterial bleeding after extension of a sphincterotomy). These two patients had an uneventful recovery.

Two patients (3\%), one with and one without a gallbladder, had stone recurrence at 27 and 30 months after ESWL, respectively. The first patient could be treated with a renewed endoscopic extraction, and the other had a successful repeated ESWL treatment.

One patient had a subcapsular hematoma of the right kidney, as demonstrated on US. The hematoma resolved without clinical consequences. Notwithstanding antibiotic prophylaxis, one patient developed sepsis with a positive blood culture (Escherichia coli). This patient received adequate medical treatment. There was no mortality after ESWL and adjuvant treatments.

\section{Group III}

Thirteen patients had stone fragmentation $(76 \%)$, of whom 11 $(65 \%)$ had immediate pain relief after ESWL. The other two patients, with fragmentation but without clearance of stones, had recurrent pain attacks and consequently underwent a side-to-side pancreatojejunostomy 12 and 24 months after ESWL, respectively (Table 4). Seven patients (41\%) had complete stone clearance (in three the pancreatic duct cleared spontaneously after ESWL, and in four the duct was cleared after 2 days of lavage with sterilized water). To date, none has had recurrent abdominal pain except one patient who had a pain attack after a large alcohol intake. The median follow-up of these seven patients was 22 months (6-41 months). Of the four patients without stone fragmentation, three had a side-to-side pancreaticojejunostomy. However, all three of them still report abdominal pain 38, 31, and 14 months after the operation, respectively. One has developed insulin-dependent diabetes mellitus.

The only complication directly after ESWL was an exacerbation of pancreatitis in one patient that could be treated medically. Again, there was no mortality after ESWL.

\section{Discussion}

The role of ESWL in surgery is becoming clarified. With the results achieved in our patients and in other patient series, more reasoned statements can be made now. Instead of optimistic or pessimistic views, patients benefit most from a well established treatment scheme in which the different modalities have their own, though sometimes limited, role.

\section{Gallbladder Stones}

(Laparoscopic) cholecystectomy remains the gold standard as the treatment for symptomatic cholecystolithiasis [24, 25]. Cholecystectomy carries morbidity and mortality rates of about $10 \%$ to $30 \%$ and $0.1 \%$ to $0.3 \%$, respectively, and these rates increase with age [25]. With laparoscopic cholecystectomy these figures may be lower, but the higher incidence of bile duct injuries gives reason for concern [26]. There is no reported mortality associated with ESWL of gallbladder stones, and the rate of major complications is low $[7,11]$. In our series, nine patients $(7 \%)$ had common bile duct obstruction, and one patient had an acute cholecystitis after ESWL.

After optimistic initial reports in which finally more than $90 \%$ of the selected patients became stone-free [7], less favorable results gave rise to pessimistic comments [27]. However, most patient series have reported overall stone-free rates at 12 
months of $30 \%$ to $84 \%$, depending largely on stone characteristics [10-14, 28-31]. This point is in accordance with our own findings-that ESWL therapy is found to be more effective for solitary than multiple stones, for radiolucent than slightly calcified stones, and for smaller than for larger stones. In view of the above, we think that only patients with a high operative risk (ASA classification III-IV [32]) or patients who reject an operation should undergo ESWL, provided they comply with strict criteria to achieve the highest possible stone clearance rate. We estimate this rate to be about 50\% after 1 year.

\section{Common Bile Duct Stones}

In the case of choledocholithiasis, surgical common bile duct exploration is an accepted therapy but carries a considerable mortality rate, which may be as high as $8 \%$ in the elderly or in high-risk patients [33-35]. Among this population, the treatment of choice is endoscopic sphincterotomy (ES) [36-38]. However, in about $10 \%$ of the cases it proves impossible to clear the bile ducts with endoscopy alone $[8,36,39]$. The natural history of common bile duct stones, with or without ES, still is not well known [37]. However, all our patients were symptomatic and needed therapy for the short term. In these patients ESWL is an attractive alternative to surgery: Stone clearance was achieved in $65 \%$ of our patients and in up to $88 \%$ in other studies [8, $18-21,40,41]$.

The failure rate can be due to the possibility of false positivity during radiologic targeting via a biliary drain. The morbidity rate of ESWL of common bile duct stones is low: Macrohematuria (in $2-11 \%$ of the patients) and hemobilia (2-8\%) are reported to resolve within a few days $[8,18,20]$. Septic fever in $3 \%$ to $6 \%$ of the cases is often regarded as an exacerbation of already existing cholangitis $[8,18,19]$. There has not been any ESWL-related mortality, but mortality associated with the adjuvant endoscopic or percutaneous procedures, which is about $1 \%$ [36, 39], must be borne in mind. At least in the patient with an increased operative risk, ESWL should be considered before surgery after failure of endoscopic measures.

\section{Pancreatic Stones}

Although it remains uncertain whether pancreatic stones are the main cause of the pain in chronic calcifying pancreatitis (CCP), 11 of 13 patients with stone fragmentation were free of abdominal pain directly after the ESWL treatment (Table 4). Whether fragmentation without stone clearance can lead to long-lasting pain relief is doubtful. In our series two of six patients with stone fragmentation but no stone clearance had recurrent abdominal pain and an operation after ESWL. The other four patients have reported pain relief only at limited follow-up (median 7 months, range 5-10 months). ESWL resulted in clearance of stone material in $41 \%$ of our patients, and all of them have pain relief to date.

Stone clearance in 59\% of 123 patients with CCP, treated with ESWL and subsequent endoscopic drainage, has been reported [22]. The authors emphasized the importance of deep endoscopic drainage in the pancreatic duct after ESWL.

The ESWL technique compares favorably with an operation for pain relief in CCP: It is noninvasive, there is no need for general anesthesia, no mortality has been reported, and the number of complications is low (in our series one exacerbation of pancreatitis). It is unlikely that pancreatic insufficiency will be induced by ESWL. Furthermore, the hospitalization time is short (about 3 days per ESWL session). Pancreatic surgery is accompanied by considerable morbidity and mortality (rates of $20-40 \%$ and $2-5 \%$, respectively) $[42,43]$. In large surgical series, long-lasting pain relief cannot be achieved in $20 \%$ to $40 \%$ of the cases [42-46]. In view of the above, a randomized trial comparing ESWL with surgery or the natural history of this disease is warranted.

In conclusion, if a decision must be made about whether to operate on a patient with CCP or treat him or her with ESWL followed by endoscopic drainage, we think that ESWL is the better alternative. It seems important to achieve stone clearance and not mere stone fragmentation. Of course abuse of alcohol must be treated as a condition that may interfere with the success of this therapy of CCP.

\section{Résumé}

Pendant ces 12 dernières années, la lithotritie extracorporelle (LE) a été proposée pour remplacer certaines techniques chirurgicales. Dans l'intérêt du patient, il était important de déterminer le rôle précis de la LE en chirurgie. Nous avons suivi prospectivement 133 patients ayant une lithiase vésiculaire, 80 , une lithiase de la voie biliaire principale et 17 , des calcificatins pancréatiques, tous traités par un lithotriteur de deuxième génération le Siemens Lithostar (Siemens, Erlangen, RFA). Les résultats suggérent que la $L E$ a un rôle limité dans la lithiase vésiculaire, réservée uniquement aux les patients à très haut risque chirurgical et à ceux qui refusent l'intervention. Chez les patients ayant une lithiase de la voie biliaire principale, son rôle se borne au traitement des patients âgés, inopérables chez lequels la sphinctérotomie est un échec. Enfin, la LE pourrait être le traitement de choix chez les patients ayant des douleurs résistantes au traitement médical dans la pancréatite calcifiante chronique.

\section{Resumen}

A partir de 1980 la litroticia extracorpórea por ondas de shock (LEOS) ha sido eficazmente utilizada en la urolitiasis y ha venido a suplantar casi totalmente al tratamiento quirúrgico. $\mathrm{La}$ LEOS de cálculos de la vesícula biliar está en uso desde 1985, y los primeros informes sobre LEOS de cálculos del colédoco y del páncreas aparecieron en 1989. A pesar del entusiasmo inicial, bien pronto se hicieron evidentes las restricciones sobre su aplicación, especialmente en el caso de cálculos de la vesícula biliar. En el interés del paciente, aparece importante definir el papel de la LEOS en la cirugía. Hemos tratado de hacerlo comparando nuestros pacientes, seguidos en forma prospectiva, con los de otras series. Nuestro grupo ha tratado 133 casos de colelitiasis, 80 de coledocolitiasis y 17 de cálculos pancreáticos con un litotritor de segunda generación, el Lithostar de Siemens (Siemens, Erlangen, Alemania). Los resultados sugieren un papel limitado de la LEOS en colelitiasis, entidad para la cual se usa sólo en pacientes de muy alto riesgo operatorio o en aquellos que rehusan la operación. En la coledocolitiasis la LEOS aparece como parte integral del tratamiento en pacientes de edad avanzada, en quienes resulte 
imposible la remoción endoscópica de los cálculos. Finalmente, la LEOS puede representar la primera opción en el manejo del dolor intratable en pacientes con pancreatitis crónica calcificada.

\section{References}

1. Coleman, A.J., Saunders, J.E., Crum, L.A., Dyson, M.: Acoustic cavitation generated by an extracorporeal shockwave lithotriptor. Ultrasound Med. Biol. 13:69, 1987

2. Delius, M., Brendel, W., Heine, G.: A mechanism of gallstone destruction by extracorporeal shockwaves. Naturwissenschaften $75: 200,1988$

3. Ferruci, J.T.: Biliary lithotripsy: 1989. AJR 153:15, 1989

4. Chaussy, Ch., Brendel, W., Schmiedt, E.: Extracorporeally induced destruction of kidney stones by shock waves. Lancet $2: 1265$, 1980

5. Chaussy, C.G., Fuchs, G.J.: Current state and future developments of noninvasive treatment of human urinary stones with extracorporeal shock wave lithotripsy. J Urol 141:782, 1989

6. Sauerbruch, T., Delius, M., Paumgartner, G., et al.: Fragmentation of gallstones by extracorporeal shock waves. N. Engl. J. Med. $314: 818,1986$

7. Sackmann, M., Delius, M., Sauerbruch, T., et al.: Shock-wave lithotripsy of gallbladder stones: the first 175 patients. N. Engl. J. Med. 318:393, 1988

8. Sauerbruch, T., Stern, M., Study Group for Shock-Wave Lithotripsy of Bile Duct Stones: Fragmentation of bile duct stones by extracorporeal shock waves: a new approach to biliary calculi after failure of routine endoscopic measures. Gastroenterology 96:146, 1989

9. Sauerbruch, T., Holl, J., Sackmann, M., Paumgartner, G.: Extracorporeal shock wave lithotripsy of pancreatic stones. Gut 30:1406, 1989

10. Schoenfield, L.J., Berci, G., Carnovale, R.L., et al.: The effect of ursodiol on the efficacy and safety of extracorporeal shock-wave lithotripsy of gallstones: the Dornier National Biliary Lithotripsy Study. N. Engl. J. Med. 323:1239, 1990

11. Sackmann, M., Pauletzki, J., Sauerbruch, T., Holl, J., Schelling, G., Paumgartner, G.: The Munich gallbladder lithotripsy study: results of the first 5 years with 711 patients. Ann. Intern. Med. II4:290, 1991

12. Den Toom, R., Vergunst, H., Nijs, H.G.T., Brakel, K., Laméris, J.S., Terpstra, O.T.: Electromagnetic lithotripsy of gallbladder stones: a wide range of inclusion criteria. Am. J. Gastroenterol. 87:497, 1992

13. Darzi, A., El-Sayed, E., O'Morain, C., Tanner, W.A., Keane, F.B.V.: Piezoelectric lithotripsy for gallstones: analysis of results in patients with extended selection. Br. J. Surg. 78:163, 1991

14. Mosnier, H., Guivarc'h, M.: Safety and efficacy of piezoelectric extracorporeal lithotripsy (PEL) for gallstones: preliminary results. Hepatology 8:1256, 1988

15. Sackmann, M., Ippisch, E., Sauerbruch, T., Holl, J., Brendel, W., Paumgartner, G.: Early gallstone recurrence after successful shock wave therapy. Gastroenterology 98:392, 1990

16. Villanova, N., Bazzoli, F., Taroni, F., et al.: Gallstone recurrence after successful oral bile acid treatment: a 12-year follow-up study and evaluation of long-term postdissolution treatment. Gastroenterology 97:726, 1989

17. O'Donnell, L.D.J., Heaton, K.W.: Recurrence and re-recurrence of gall stones after medical dissolution: a longterm follow-up. Gut 29:655, 1988

18. Bland, K.I., Jones, R.S., Maher, J.W., et al.: Extracorporeal shock-wave lithotripsy of bile duct calculi: an interim report of the Dornier U.S. bile duct lithotripsy prospective study. Ann. Surg. 209:743, 1989

19. Den Toom, R., Nijs, H.G.T., van Blankenstein, M., Laméris, J.S., Schröder, F.H., Terpstra, O.T.: Extracorporeal shock wave treatment of common bile duct stones: experience with two different lithotriptors at a single institution. Br. J. Surg. 78:809, 1991

20. Dobrilla, G., de Pretis, G., Felder, M., et al.: Extracorporeal shock wave lithotripsy in bile duct stones refractory to papillosphincterotomy. Eur. J. Gastroenterol. Hepatol. 4:475, 1992

21. Nicholson, D.A., Martin, D.F., Tweedle, D.E.F., Rao, P.N.: Management of common bile duct stones using a second-generation extracorporeal shockwave lithotriptor. Br. J. Surg. 79:811, 1992

22. Delhaye, M., Vandermeeren, A., Baize, M., Cremer, M.: Extracorporeal shock-wave lithotripsy of pancreatic calculi. Gastroenterology 102:610, 1992

23. Axon, A.T.R., Classen, M., Cotton, P.B., et al.: Pancreatography in chronic pancreatitis; international definition. Gut 25:1107, 1984

24. Schirmer, B.D., Edge, S.B., Dix, J., Hyser, M.J., Hanks, J.B., Jones, R.S.: Laparoscopic cholecystectomy: treatment of choice for symptomatic cholelithiasis. Ann. Surg. 213:665, 1991

25. McSherry, C.K.: Cholecystectomy: the gold standard. Am. J. Surg. 158:174, 1989

26. Southern Surgeons Club: A prospective analysis of 1518 laparoscopic cholecystectomies. N. Engl. J. Med. 324:1073, 1991

27. Maglinte, D.D.T., Graffis, R., Jordan, L., Chua, G.T., Johnson, A.C., Crossin, J.: Extracorporeal shock wave lithotripsy of gallbladder stones: a pessimistic view. Radiology 178:29, 1990

28. Ponchon, T., Barkun, A.N., Pujol, B., Mestas, J.L., Lambert, R.: Gallstone disappearance after extracorporeal lithotripsy and oral bile acid dissolution. Gastroenterology 97:457, 1989

29. Classen, M., Cremer, M., Faustini, S., et al.: Electromagnetic shock-wave lithotripsy of gallbladder calculi: multicentered preliminary report on experience with 276 patients. Hepato gastroenterology 37:425, 1990

30. Meiser, G., Heinerman, M., Lexer, G., Boeckl, O.: Aggressive extracorporeal shock wave lithotripsy of gall bladder stones within wider treatment criteria: fragmentation rate and early results. Gut 33:277, 1992

31. Elewaut, A., Crape, A., Afschrift, M., Pauwels, W., De Vos, M., Barbier, F.: Results of extracorporeal shock wave lithotripsy of gall bladder stones in 693 patients: a plea for restriction to solitary radiolucent stones. Gut 34:274, 1993

32. Owens, W.D., Felts, J.A., Spitznagel, E.L.: ASA physical status classifications: a study of consistency of ratings. Anesthesiology 49:239, 1978

33. Doyle, P.J., Ward-McQuaid, J.N., McEwen Smith, A.: The value of routine preoperative cholangiography-a report of 4,000 cholecystectomies. Br. J. Surg. 69:617, 1982

34. McSherry, C.K., Glenn, F.: The incidence and causes of death following surgery for non-malignant biliary tract disease. Ann. Surg. 191:271, 1980

35. Vellacott, K.D., Powell, P.H.: Exploration of the common duct: a comparative study. Br. J. Surg. 66:389, 1979

36. Cotton, P.B.: Endoscopic management of bile duct stones (apples and oranges). Gut $25: 587,1984$

37. Johnson, A.G., Hosking, S.W.: Appraisal of the management of bile duct stones. Br. J. Surg. 74:555, 1987

38. Zimmon, D.S.: Alternatives to cholecystectomy and common duct exploration. Am. J. Gastroenterol. 83:1272, 1988

39. Lambert, M.E., Betts, C.D., Hill, J., Faragher, E.B., Martin, D.F., Tweedle, D.E.F.: Endoscopic sphincterotomy: the whole truth. Br. J. Surg. 78:473, 1991

40. Lindström, E., Borch, K., Kullman, E.P., Tiselius, H.G., Ihse, I. Extracorporeal shock wave lithotripsy of bile duct stones: a single institution experience. Gut 33:1416, 1992

41. Weber, J., Adamek, H.E., Riemann, J.F.: Extracorporeal piezoelectric lithotripsy for retained bile duct stones. Endoscopy 24:239, 1992

42. Mannell, A., Adson, M.A., McIlrath, D.C., Ilstrup, D.M.: Surgical management of chronic pancreatitis: long-term results in 141 patients. Br. J. Surg. 75:467, 1988

43. Prinz, R.A., Greenlee, H.B.: Pancreatic duct drainage in 100 patients with chronic pancreatitis. Ann. Surg. 194:313, 1981

44. Bradley, E.L., III: Long-term results of pancreatojejunostomy in patients with chronic pancreatitis. Am. J. Surg. 153:207, 1987

45. Ihse, I., Borch, K., Larsson, J.: Chronic pancreatitis: results of operations for relief of pain. World J. Surg. 14:53, 1990

46. Greenlee, H.B., Prinz, R.A., Aranha, G.V.: Long-term results of side-to-side pancreaticojejunostomy. World J. Surg. 14:70, 1990 